\title{
Retro-Inverso Peptide
}

National Cancer Institute

\section{Source}

National Cancer Institute. Retro-Inverso Peptide. NCI Thesaurus. Code C1963.

Peptides built of $D$-amino acids in the reversed sequence order. These may adopt structures similar to their L-counterparts while being more resistant to proteolytic degradation. 